\title{
Retrospective Study of Epidermal Parasitic Skin Diseases amongst Out- Patients of Skin Diseases Hospital, Maiduguri, Borno State, Nigeria
}

\section{${ }^{1} \mathrm{BIU}, \mathrm{AA} ;{ }^{2} \mathrm{MACHINA}, \mathrm{IB} ;{ }^{2} \mathrm{NGOSHE}, \mathrm{IY} ;{ }^{* 1}$ ONYICHE, ET}

\author{
${ }^{I}$ Department of Veterinary Parasitology and Entomology, Faculty of Veterinary Medicine, ${ }^{2}$ Department of Microbiology, Faculty of \\ Science, University of Maiduguri, P. M. B. 1069, Maiduguri, Nigeria. *Corresponding author E-mail Address: eonyiche@yahoo.com \\ Phone: +23408037035135
}

\begin{abstract}
A ten year retrospective study (1997-2006) was undertaken to determine the prevalence of Epidermal Parasitic Skin Diseases (EPSD) among out-patients from the skin diseases hospital in Maiduguri, Borno state. Out of 10,000 out-patients examined during the study period, 3527(35.27\%) where infected with EPSD. Of this number, 2819(79.9\%) were infected with scabies and 708 (20.1\%) with Cutaneous Larva Migrans (CLM). Retroprevalence among age revealed $1912(67.83 \%)$ for the young and $907(32.17 \%)$ for adults infected with scabies and $418(59.04 \%)$ and $290(40.96 \%)$ for adults infected with CLM. Similarly, sex wise prevalence reveals that the males had $2031(72.05 \%)$ and $501(70.76 \%)$ for scabies and CLM scabies $(\mathrm{p}<0.05)$, while females had $788(27.95 \%)$ and $207(29.24 \%)$ respectively for scabies and CLM ( $<<0.05)$. Based on cumulative monthly distribution, it was most prevalent between May and September for both scabies and CLM out- patients. Adequate attention should be accorded to the risk factors such as lack of adequate sanitation, poor hygiene and overcrowding which when eliminated or reduced will reduce the burden of the disease.
\end{abstract}

DOI: https://dx.doi.org/10.4314/jasem.v22i2.14

COPYRIGHT: Copyright $\odot 2018$ Biu et al. This is an open access article distributed under the Creative Commons Attribution License (CCL), which permits unrestricted use, distribution, and reproduction in any medium, provided the original work is properly cited

DATES: First received 03 December 2017; Received in revised form 02 February 2018; Accepted

2018

Keywords: Epidermal, Parasitic, Skin diseases, Scabies, CLM,

The skin diseases hospital in Maiduguri Borno State was first established in 1978 as a leprosy center, but was later converted to a skin diseases hospital in 1988 and provides health care services to the grass roots particularly on health care education pertaining to personal hygiene and food and nutrition and acquires its funding from non- governmental organizations (NGO's) in collaboration with the Federal Ministry of Health. A great majority of tropical diseases in one way or another are intricately linked with poverty (Traub et al. 2002).

Scabies refers to the various skin lesions produced by female mites, and their eggs and scybala that are deposited in the epidermis, leading to delayed-type hypersensitivity reaction (Hengge et al., 2006). It remains one of the commonest of all skin diseases of all ages in many regions in resource-poor societies. Likewise, cutaneous larva migrans is caused by penetration of hookworm larvae usually from dogs or cats, into the skin of humans. It causes creeping eruption on the skin which is usually self-limited (Heukelbach et al., 2004)

Both Scabies and Cutaneous larva migrans are largely common because of the highly conducive eco-climate, human and social factors (Heukelbach $e t$ al. 2002), with a high burden particularly in developing countries and amongst resource- poor populations (Hay, et al. 2012). However, these epidermal parasitic skin diseases (EPSD) are rarely acknowledged as public health problems and have been widely neglected by the scientific community and health care providers, hence the study was undertaken to provide relevant data on the retroprevalence of Epidermal Parasitic Skin Diseases (EPSD) among out-patients from the skin diseases hospital in Maiduguri, Borno state.

\section{MATERIALS AND METHODS}

Records of out-patients documented between 1997 and 2006 (a span of ten (10) years) were reviewed with particular reference to Scabies and Cutaneous Larva Migrans. Monthly occurrence of the two epidermal parasitic skin diseases (EPDS) was taken down in relation to the age and sex of the outpatients. The data obtained were summarized in table and bar chart. Student t-test was performed to determine significant difference between variables.

\section{RESULTS AND DISCUSSION}

Table 1 below shows the prevalence of epidermal parasitic skin diseases based on the sex and age of out-patient examined. Out of the 10,000 out-patients 
examined $3527(35.27 \%)$ were infected with 2819 (79.9\%) for scabies and $708(20.1 \%)$ for CLM ( $\mathrm{p}<$ $0.05)$. This is similar to that reported by Schuster $e t$. al., (2011). Scabies and CLM are common among impoverished rural and urban communities in countries with hot climates and belong to the category of neglected tropical diseases (NTD) (Hengge et al. 2006). However, EPSD is irregular, and incidence and prevalence vary in relation to area and population.

Table 1: Prevalence of Epidermal Parasitic Skin Diseases based on the Sex and Age of Out-patients

\begin{tabular}{llll}
\hline Variables & Number of Patients (\%) & \multicolumn{2}{l}{ Number of Infected patients $(\%)$} \\
Scabies & Cutaneous Larva Migrans \\
\hline Age & & & \\
Young (<18yrs) & $2370(67.19)$ & $1912(67.83)^{\mathrm{a}}$ & $418(59.04)^{\mathrm{a}}$ \\
Adult $(\geq \mathbf{1 8 y r s})$ & $1157(32.80)$ & $907(32.17)^{\mathrm{b}}$ & $290(40.96)^{\mathrm{b}}$ \\
Total & $3527(100.00)$ & $2819(100.00)$ & $708(100.00)$ \\
Sex & & & \\
Male & $2496(70.77)$ & $2031(72.05)^{\mathrm{a}}$ & $501(70.76)^{\mathrm{a}}$ \\
Female & $1031(29.23)$ & $788(27.95)^{\mathrm{b}}$ & $207(29.24)^{\mathrm{b}}$ \\
Total & $3527(100.00)$ & $2819(100.00)$ & $708(100.00)$ \\
\hline
\end{tabular}

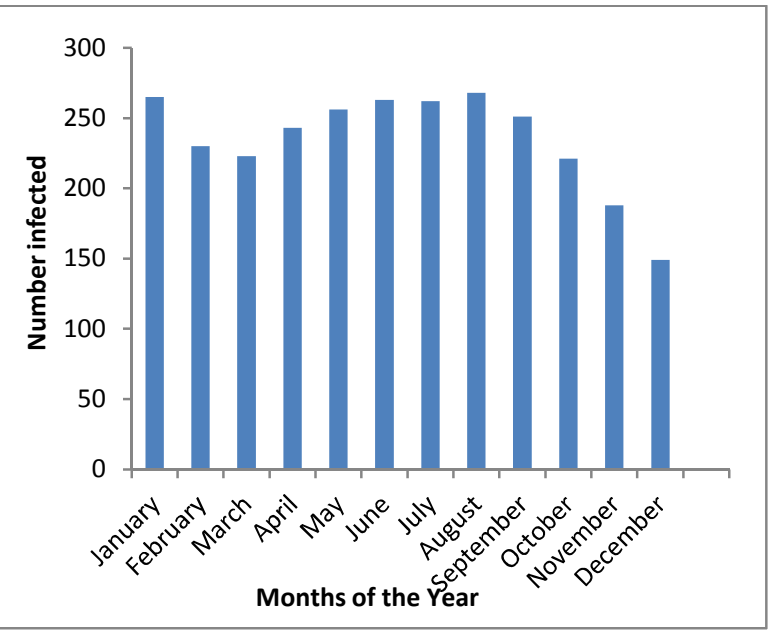

Fig 1: Cumulative Monthly Distribution of Scabies amongst Outpatients in Maiduguri, Borno State (1997 - 2006).

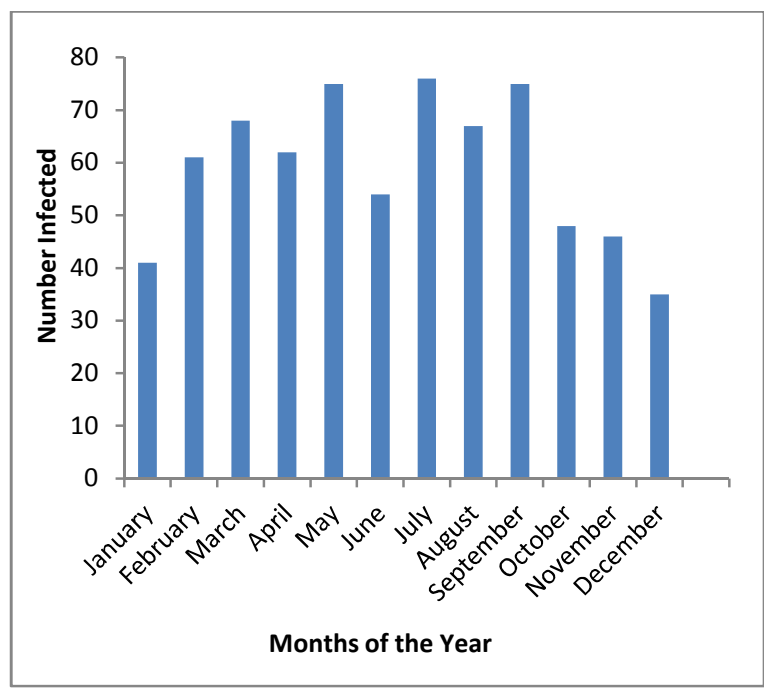

Fig 2: Cumulative Monthly Distribution of Cutaneous Larva Migrans amongst Out-patients in Maiduguri, Borno State (1997 2006).
Prevalence of EPSD amongst age revealed 1157 $(32.8 \%)$ for adults with $907(32.17 \%)$ for scabies and $290(40.96 \%)$ for CLM $(\mathrm{p}<0.05)$ while young outpatients had $2370(67.2 \%)$ with 1912 (67.83\%) for scabies and $418(59.04 \%)$ for CLM $(\mathrm{p}<0.05)$. Also, sex wise males had $2496(70.8 \%)$ with 2031 $(72.05 \%)$ for scabies and $501(70.76 \%)$ for CLM $(\mathrm{p}<0.05)$ while females had $1031(29.2 \%)$ with $788(27.95 \%)$ for scabies and 207(29.24\%) for CLM $(\mathrm{p}<0.05)$ (Table 1).

This agrees with Feldmeier and Heukelbach, (2009) and Hay, et al., (2012) that children are the most vulnerable but differs on their findings on sex".

However, factors responsible for the high burden of EPSD in resource poor communities are complex and have not been clarified, but it has been suggested that crowding, sharing of beds, frequent population movements, poor hygiene lack of access to health care, inadequate treatment, malnutrition and social attitude are contributors, and it is difficult to disentangle the relative importance of economic, environmental and behavioral factors, since they frequently coexist (Singg, 2015; Jose et al. 2016).

The cumulative monthly distributions of EPSD are shown in Figure 1 and 2 above for scabies and CLM respectively. Furthermore, prevalence was also significantly higher between May and September within which falls the rainy season. This agrees with Heukelbach et al., (2004); Hengge et al., (2006); Feldmeier and Heukelbach, (2009) that scabies and hookworm related cutaneous larva migrans (HrCLM) have seasonal variation of disease occurrence with most cases in the rainy season.

Conclusion: In conclusion, the burden of EPSD's are reportedly high in Maiduguri, and this could be attributed to risk factors such as lack of adequate sanitation, poor hygiene and overcrowding. 
Therefore, the existence of these epidermal diseases in the study area necessitates the need for an urgent and comprehensive prevention strategy be put in place to curtail and reduce the prevalence and probable eradication from this area.

Acknowledgements: We thank the management of the Borno skin disease hospital for granting us access to their records.

\section{REFERENCES}

Feldmeier, H; Heukelbach, J (2009). Epidermal parasitic skin diseases: a neglected category of poverty associated plagues. Bull. World Health Organ. 87:152-159

Hay, RJ; Steer, AC; Engelman, D; Walton, S (2012). Scabies in the developing world: its prevalence, complications and management. Clin. Microbiol. Infect. 18:313-323

Hengge, UR; Curie, BJ; Jäger, G; Lupi, O; Schwartz, RA (2006). Scabies: a ubiquitous neglected skin disease: Review. Lancet Infect. Dis. 6: 769-79

Heukelbach, J; Mencke, N; Feldmeier, H (2002). Cutaneous larva migrans and tungiasis: the challenge to control zoonotic ectoparasitoses associated with poverty. Trop. Med. Int. Health, 7:907-10.
Heukelbach, J; Winter, B; Wilcke, T; Muehlea, M; Albrecht, S; de'Oliveira, FAS; Kerr-Pontes, LRS; Liesenfeld, O; Feldmeier, H (2004). Selective mass treatment with ivermectin to control intestinal helminthiases and parasitic skin diseases in a severely affected population. Bull. World Health Organ. 82(8): 563-571

Jose, MR; Moles-Poveda, P; Tessema, D; Kedir, M; Safayo, G; Tesfasmariam, A; Reyes, F; Belinchon, I (2016). Skin problems in children under five years old at a rural hospital in southern Ethiopia. Asian Pacific J. Trop. Biomed. 6(7): 625-629

Schuster, A; Lesshafft, H; Talhari, S; Guedes de Oliveira, S; Ignatious, R; Feldmeier, H (2011). Life quality impairment caused by hookworm related cutaneous larva migrans in resource poor communities in Manaus, Brazil, Plos Negl. Trop. Dis. 5(11): e 1355.

Singg, S (2015). Scabies awareness and fear of scabies scale- 10. J. Clin. Case Stu 1(1): do I http//dxdoi.org/10. 16966/2471-4925 102.

Traub, RJ; Robertson, ID; Irwin, P; Mencke, N; Thompson, RCA (2002). The role of dogs in the transmission of gastrointestinal parasites in remote tea growing community in the Northeast India. Am. J. Trop. Med. Hyg. 67 (5): 539-45. 